\title{
12. THE USE OF BIBLIOMETRICS IN ADULT EDUCATION RESEARCH
}

To be, say, a formidable club player, I must be recognized as such by those I recognize as such. My recognitive attitudes can define a virtual community, but only the reciprocal recognition by those I recognize can make me actually a member of it, accord me the status for which I have implicitly petitioned by recognizing them.

- Brandom, 2008, p. 71

\section{INTRODUCTION}

The aim of this chapter is to introduce a methodological approach that can be used in order to analyze how the adult education research field is shaped through research practices, measurement standards and indexation. More specifically, we focus on three formative dimensions that we argue play a significant role in constructing "the rules of the game" in contemporary academia: (i) indexation, (ii) publications and (iii) citations. Our account is nowhere close to exhaustive but outlines how bibliographic data and bibliometric methodology can be used. Hence, to build our argument we draw on the research traditions of bibliometrics which, in the last few decades, has become linked to a highly controversial subject. Namely, how the reward system of the modern university should function. What will be the basis of 'quality' assessments of universities? How will merit be fought about and money distributed across different universities and disciplines?

The emergence of large-scale statistics in Western societies has always had a close connection to the state and the role it has in steering and governing a given population (Desrosiéres, 2008). Since the early ground-breaking work of bibliometricans such as de Solla Price's (1965) and Merton (1973), citations and publication patterns of scholars has been used to understand how researchers behave and relate to one another's work. In the heyday of bibliometrics the measurement of citations could, quite rightly we think, be treated as signs of internal collegial recognition. However, since then citations and publications within higher education has been dragged into a standardized evaluation regime that differs considerably from the situation studied by the forerunners of contemporary bibliometrics. Apparently lacking any other comparative measurements governments and management boards across a wide range of countries have begun to turn towards the standardized output variables linked 
to recognized databases. As with all economic incentives orchestrated by the state, standardized evaluations can have "perverse effects" as soon as agents start to adjust their behaviour to fit what is currently being measured and evaluated (Hoskin, 1996).

However, the degree to which higher education policies have incorporated bibliometric performance indicators varies across countries and tend to change over time. For example, the Research Excellence Framework (REF) in the UK drew on citation analyses as part of the research assessment (Martin, 2011; Brown, 2014). Another, arguably even more aggressive version of this assessment praxis, is currently and has for many years been enacted in Sweden where the government divides a substantial share of its research funding to higher education institutions based purely on a small number of performance indicators related to the publication and citation rates in journals listed in Web of Science (Ministry of Education, 2007). A third version, combining collegial assessment and production matrixes, is the so called "Norwegian list", in which both articles and books are counted, but differently so depending on where it is published and how evaluators assess its impact (Larsson, 2009).

It is tempting and, indeed appropriate, to critique these policy developments for the highly reductionistic and futile ways it deals with the complex issue of quality assessment and collegial recognition in higher education (Gingras, 2016; Karpik, 2011; Larsson, 2009). Yet the research tradition that once gave rise to the convention of studying research practices and scholarly acknowledgement through publications and citations still provide a series of important lessons for those interested in understanding the construction and formation of research traditions and the way scholars recognize and assign value to each other's work.

This chapter builds on previous research conducted on the field of adult educational research and aim to provide a short introduction to the use of bibliometrics (Nylander et al., 2018; Fejes \& Nylander, 2014, 2015, 2018, 2019). To be sure, bibliometric research has evolved greatly since the foundational contributions of de Solla Price and Merton. This contribution can be seen as an effort to provide a "descriptive cartography" of the field of adult educational research (Gingras, 2016, p. 75) and analyze how this relates to the dynamics and tendencies in academic research more widely. ${ }^{1}$ Throughout the chapter we will highlight the importance of geographical and linguistic boundaries in assessing what is given scholarly recognition within the adult educational research field. We conclude that bibliometric methods remain a powerful tool to map out localized research communities and their publication and citation practices. By conducting these kinds of analysis, we believe it is possible to give a panoramic view of what kind of research that is being published and cited by colleagues as well as to foster reflexivity on the fundamental questions posed in any given scientific subfield (Bourdieu \& Wacquant, 2004).

\section{INDEXATION AND THE DOMINANT DATABASES}

In the current landscape of higher education, the role of databases such as Web of Science and Scopus is paramount in "setting the rules" of which journals that "count" 
(cf. Archambault et al., 2009; Bonitz et al., 1997; Larsson, 2009). Or put in another way, by introducing certain measurements, based on certain databases, politicians and university managers steer academics work towards certain publication outputs. This means that Web of Science and Scopus are assigned the role of rulers of the rules of contemporary academia and that journals indexed in these databases, their editors and reviewers function as gatekeepers of what is deemed as 'high quality' research. In effect the journals are also deciding on which researchers that should be deemed worthy of contributing to the field and which ones that is not. Thus, questions such as what kinds of journals that are indexed in these databases becomes pivotal to explore. In what language are these indexed journals published? Who can publish in their first language in the journals that "count"? Where are the journals published, or rather, are there a "bias" in terms of geography of journals? Even though, many of these indexed journals have not asked to become gatekeepers in the various national contexts they have nevertheless increasingly been awarded this role.

First thing we need to look closer at is what kinds of journals these databases include in the first place. Turning to the database that is assigned the highest status in many locations, the Web of Science (WoS), we can begin to look at in what countries that are represented in the journals that are indexed, and in what language their articles are written. Here, we focus on those journals indexed in the category "education" and "educational research" as per the listing for 2016. We also compare 2016 to the listing of 2011, in order to see how the database have developed over time.

In total there are 235 articles indexed in the category of education and educational research for the year 2016, whereas a total of 216 journals were included for 2011. Country of publisher origin, as listed in the database, is distributed in the following way.

The numbers illustrate that there is a clear dominance of two countries, the US and the UK. Altogether, $76 \%$ of all journals in the category education and educational research is published in these two countries. If we include all those journals published in a location where English is the first language (New Zealand, Australia, Canada and South Africa), we end up with a total percentage of $82 \%$ of all journals indexed in WoS. We can also see how there has been a slight increase of indexed journals in this category, from 216 to 235 between 2011 and 2016. In relative terms the Anglophone dominance is stable and the idea that these databases has become more 'international' over time does not seem warranted based on the available data on the location of the publishers. ${ }^{2}$

However, editorial work is not necessarily conducted in the same country as where the publisher is located. Thus, there might be a wider regional distribution of the journals as indicated above. But when we look at what language these journals are published in, the Anglophone dominance becomes even more prominent. Below is the language of publication as of 2016 and 2011.

As these results indicate, English is, not surprisingly, the hegemonic language of publication in the education research field as represented through journals indexed in the Web of Science (WoS). Perhaps more surprisingly, this position as 
E. NYLANDER ET AL.

Table 12.1. Publishers indexed in the categories Education and Educational Research included in Web of Science 2011 and 2016 by country, frequency and percentages

\begin{tabular}{|c|c|c|c|c|}
\hline Country of publisher & Freq. 2016 & Percentage 2016 & Freq. 2011 & Percentage 2011 \\
\hline UK & 92 & 39 & 81 & 38 \\
\hline USA & 87 & 37 & 80 & 37 \\
\hline Netherlands & 18 & 8 & 15 & 7 \\
\hline Australia & 8 & 3 & 7 & 3 \\
\hline Spain & 6 & 3 & 8 & 4 \\
\hline Germany & 5 & 2 & 4 & 2 \\
\hline New Zealand & 4 & 2 & 4 & 2 \\
\hline Turkey & 3 & 1 & 3 & 1 \\
\hline South Africa & 2 & 1 & 2 & 1 \\
\hline South Korea & 2 & 1 & 2 & 1 \\
\hline Mexico & 1 & 0 & 1 & 0 \\
\hline Philippines & 1 & 0 & 1 & 0 \\
\hline Lithuania & 1 & 0 & 1 & 0 \\
\hline Belgium & 1 & 0 & 1 & 0 \\
\hline Brazil & 1 & 0 & 1 & 0 \\
\hline Croatia & 1 & 0 & 2 & 1 \\
\hline Italy & 1 & 0 & 1 & 0 \\
\hline Canada & 1 & 0 & 1 & 0 \\
\hline Poland & 0 & 0 & 1 & 0 \\
\hline Total & 235 & 100 & 216 & 100 \\
\hline
\end{tabular}

the modern-day lingua franca of educational research has been strengthened over the course of recent years, as the share of multi-lingual and non-English journals has decreased further. Interesting to note, as well, is how several of the journals published in locations where is English is not the first language, also publish their journals in English.

\section{PUBLICATIONS AND CITATIONS: THE BIBLIOGRAPHIC CONTENT OF INDEXED JOURNALS}

There are currently very few journals in the adult education and learning research field indexed in the Web of Science. In the 2016 listing these journals in the field are indexed: Adult Education Quarterly (AEQ), Australian Journal of Adult Learning, Studies in Continuing Education and Vocations and Learning. Furthermore, most 
Table 12.2. Indexed journals in the categories Education and Educational Research included in Web of Science 2011 and 2016 by language, frequency and percentage

\begin{tabular}{lcccc}
\hline Language of journal & Freq. 2016 & Percent 2016 & Freq. 2011 & Percent 2011 \\
\hline English & 219 & 93 & 194 & 90 \\
Spanish & 5 & 2 & 7 & 3 \\
German & 3 & 1 & 3 & 1 \\
Multi-lingual & 3 & 1 & 3 & 1 \\
Turkish & 1 & 0 & 4 & 2 \\
Portuguese & 1 & 0 & 1 & 0 \\
Dutch & 1 & 0 & 1 & 0 \\
Croatian & 1 & 0 & 2 & 1 \\
Italian & 1 & 0 & 1 & 0 \\
Total & $\mathbf{2 3 5}$ & $\mathbf{1 0 0}$ & $\mathbf{2 1 6}$ & $\mathbf{1 0 0}$ \\
\hline
\end{tabular}

of these journals, have only been indexed in the Web of Science for a few years. If we turn to the rival database, Scopus, a few more journals in the field are included, e.g. European Journal for Research on the Education and Learning of Adults, International Journal of Lifelong Education and Journal of Education and Work. Thus, if the aim of the bibliometric analysis is to map out the content of research in adult education and lifelong learning, more specifically, it is more useful to start from Scopus rather than WoS.

So far, we have argued that the way research quality is assessed based on metrics derived from individual scholars' publications in indexed databases and in terms of citations. We have also illustrated how journals indexed in the main databases have a key role in defining quality, and how there is a substantial bias in this database in terms of where journals are published and in which language research is published. The question then is, can we identify a similar pattern in what is being published in key journals in the adult educational and learning research field? Or rather, does it matter if journals are published in English speaking countries with English as the publication language? In order build empirical evidence on such questions, we will here, firstly, conduct an analysis of the geographical distribution of first authorship of articles published within three journals in the field of adult education and learning, and secondly, outline the location of authorship for those articles that receive the highest share of citations. Thus, we can on the one hand, identify potential bias in terms of representation of authors from different parts of the world, and secondly, identify potential bias in terms of which author citations are assign greater value than others. 
We draw on the database Scopus analyzing three journals where the editorial work is located in three different continents, for further analysis: Adult Education Quarterly (US), International Journal of Lifelong Education (UK), and Studies in Continuing Education (Australia - however, the publisher is located in the UK). We have conducted an analysis of these journals during the period 2012-2018, to identify the institutional location of the first author of each article in each journal. To assess the articles that have been picked up and cited within the field we select the articles with the highest citation rates during the period, and identify the first author, and compare this to the full sample of published articles. For the period 2012-2018 we identified the share of the top 10, and top 20 highest cited articles for the period. Below, we present the results in Figure 12.1.

During the period 2012-2018 we can see how authors from the UK, US, Australia and Canada, together represent a total of $56 \%$ of all articles published. In terms of share of the 20 most cited articles, the four countries represent $67 \%$ of all articles and $66 \%$ in terms of the 10 highest cited articles. Such results indicate that a substantial dominance of authors from these four Anglophone countries. However, there are differences among the four countries. UK and Canadian authors have a relatively low number of highly cited articles as compared to Australian and US authors. This is interesting, not the least as the former have a higher share in terms of published articles. Compared to previous findings (Fejes \& Nylander, 2014), the dominance of Anglophone scholars also seems to be declining slowly in terms of both contribution to the journals and the "conversion rates" as measured through the difference between "output" and number of articles included among the "top-cited" percentages. In one

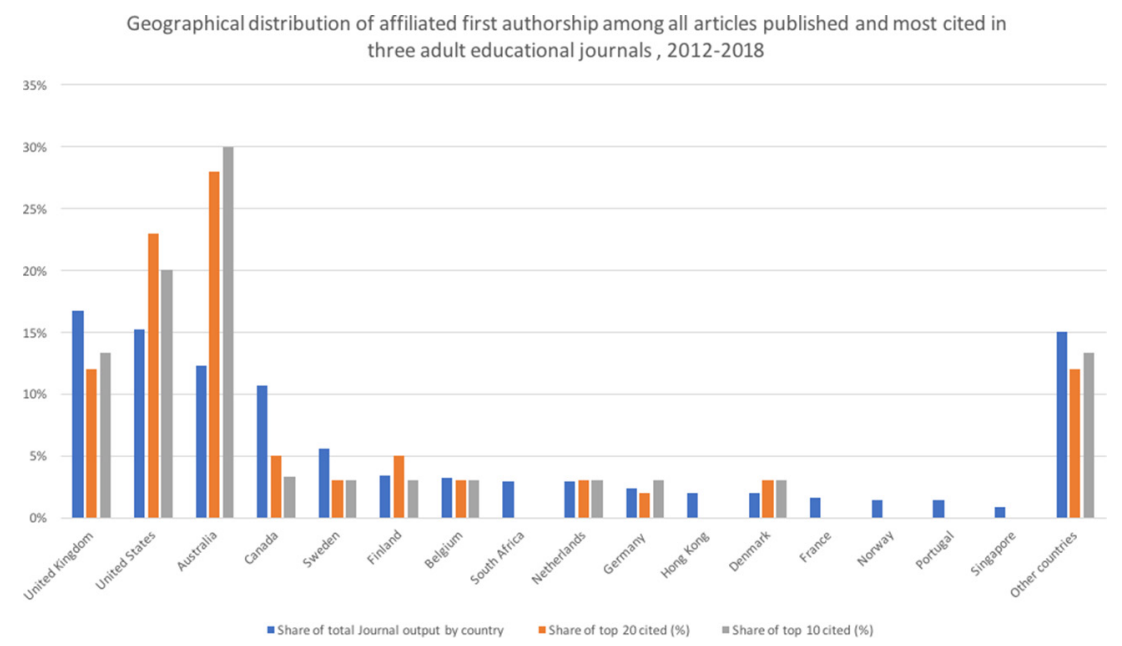

Figure 12.1. The share of published and cited content of all articles published in three adult educational journals 2012-2018 
way this can be taken as an indication that the role of these journals as international outlets for academics all around the world has been strengthen over time. However, since the sample size is rather small, particularly when it comes to the top-cited contributions, it might be wise not to read too much into the current data.

\section{FOLLOWING THE CITATION FLOWS: WHO IS CITING WHOM}

The third and final dimension of the bibliometric tradition that can be considered useful is to use citations to explore and dissect who is given recognition in the research field (Nylander et al., 2018; Larsson et al., 2019). Whereas indexation could be seen as key in shaping where researchers direct their publications and the gatekeepingfunction of editors and reviewers hold an important role in filtering out what is deemed "publishable" in the first place, that is hardly enough for understanding "who counts" in any given research field. Just as the quote by Brandom (2008) in the beginning of this chapter illustrates, one is not fully a member of a community until one is recognized as such by the members of that particular community.

In research, this dimension of scholarly recognition can also be analyzed by means of more detailed bibliographic maps based on citation data (cf. Gingras, 2016). One of the advantages of the indexation and standardization of knowledge production in databases such as WoS and Scopus is that they enable us to make use of large-scale data for exploring who is given recognition through citations.

In this final example of bibliometrics we make use of a visualization of the citations from five journals between 2006-2014 within the wider field of adult learning; adult education, continuing education, lifelong education, and workplace learning (Nylander et al., 2018). To derive the map presented on the dominating scholars in this field we have used a visualization tool called Gelphi (Bastian et al., 2009). To model the relationships of the top-cited scholars we used the default algorithm to explore social networks in Gephi ForceAtalas2 (Jacomy et al., 2014).

All the selected journals (Adult Education Quarterly, International Journal of Lifelong Education, Journal of Education and Work, Journal of Workplace Learning, Studies in Continuing Education) have acquired an indexation status in Scopus, and are thus categorized as "international" in contexts where international publication is encouraged through different methods of measuring quality in research. In all, the sample covers 1219 publications, 151,261 citation links and more than 33,000 different authors. ${ }^{3}$

Figure 12.2 illustrates how the entire research field on adult learning looks like if one takes into consideration all the citations found in these five journals between the years 2006-2014. Several central sub-clusters of authorship nodes can be observed. The most central cluster, and arguably the strongest one at the time, is created by the citation bibliographies in the tradition of sociocultural theory (in its various branches). Authors such as Etienne Wenger, Jean Lave, Stephen Billett, Yrjö Engeström, David Boud and Phil Hodkinson, represent key bibliographies in this citation cluster. It is worth noting that two bibliographies, that of Wenger and that 


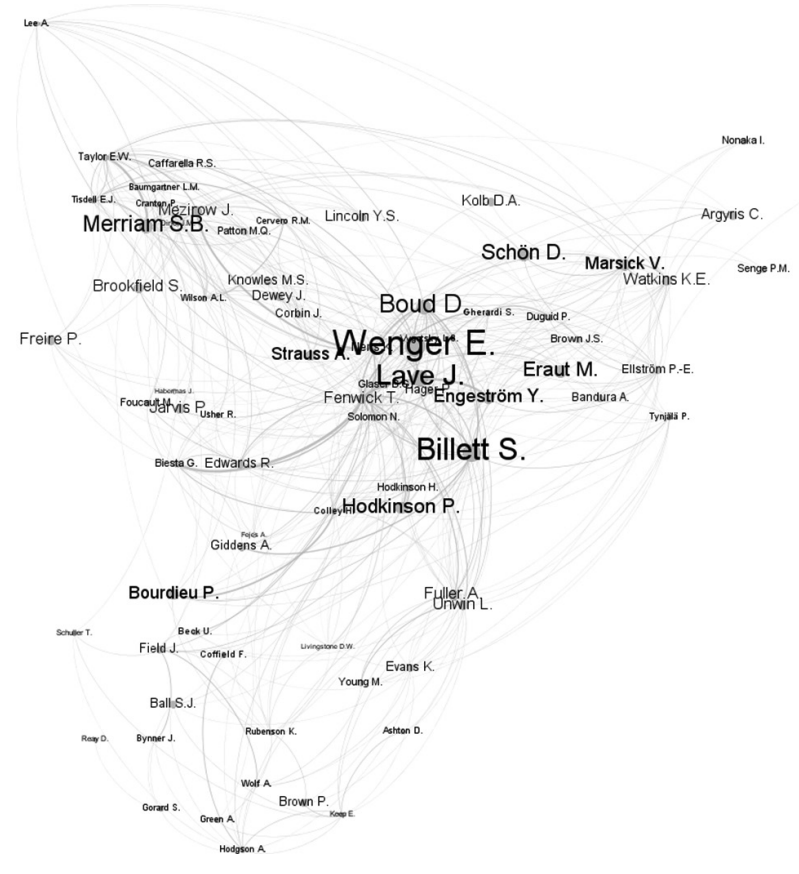

Figure 12.2. The space of citations based on accumulated number of citations in five journals on adult learning, 2006-2014

of Lave, do not themselves contribute to the building of the field by publishing in the selected journals, even though they occupy such central position. Instead these names represent what is conceived of as 'standard referencing', and is called upon as external authorities by the many researchers contributing to these journals.

Aside from references to quite a few scholars from social science in general (Bourdieu, Foucault, Beck, Giddens, Lave and Wenger) one can also trace the dominance of Anglophone scholars as most prominent names (by size). These scholars either work in or originate from countries where English is the main language spoken. One might assume that this finding is directly linked to the sample of journals chosen as these are edited in the UK, Australia, and the US. However, as we saw in the previous section, one third to almost half of the content produced in journals such as Adult Education Quarterly, International Journal of Lifelong Education, and Studies in Continuing Education comes from scholars affiliated to universities outside of the UK, US, Australia and Canada. Following the citation of individual scholars thus strengthens the image of a research field where linguistic and geographical boundaries have considerable power of shaping who is given recognition even if, as we saw from Figure 12.1, this is far from guaranteed. 
Two further points worth raising here. Firstly, there are remarkably few female authors among those most cited as illustrated in Figure 12.2. Such results are the same as those reported by Larsson et al. (2019). However, in their more elaborated analysis on the issue of gender, they illustrate how this gender imbalance in citations, is not so much an effect of internal gender discrimination within the articles produced in the field but rather an effect of the highly gendered referencing that is targeting external social scientific authorities. As the adult educational research field is rather "weak" and direct a large part of its citations to elevated scholars from outside the field, the gender imbalance here is to a large part "imported" from the patriarchal structure of the social scientific canon writ large. Secondly, we can also note that many of these authors currently hold, or have held, positions as editors and advisories to the examined journals, which raises the age old "chicken and egg" discussion of what comes first? Is it that citations come from taking on the gatekeeping function of editors within the field or is it the recognition of peers that lies behind the assignment of editor for these journals?

In the West/Southwest of the space of citations we find an aggregation of more philosophically and sociologically-oriented scholars of education, whereas on the opposite side of the figure (East/Northeast) scholars are more oriented to studying workplace learning and human resource development informed by organizational perspectives or more psychologically oriented learning theories. As previously argued by Nylander et al. (2018), the dominating role that socio-cultural theory has occupied in the field can be attributed to its "mediating" role in the field, equally adopted by scholars interested in education and workplace learning and having the power of transgressing institutional and geographical boundaries to some extent.

A surprising finding worth recognizing from this citation map is that position rendered to scholars from North American universities are not as central as one might have expected. Unlike many other social scientific fields, the assigned value of research from the US does not occupy any hegemonic position in the field of adult education and learning research, although they are still clearly visible on the map of the dominating scholars (see also, Heilbron \& Gingras, 2018). Though it is beyond the scope of our chapter to investigate what, more closely, lies behind this finding it seems warranted to claim that a few adult educational researchers in Australia have possessed more prominent positions within this field in terms of citations during this period than scholars from North American and British universities. One hypothesis that has been launched for explaining this is that the Australian scholars are forced to be more mobile and international in how they relate to other researchers and their research in the field, as they might not have the same incentives of playing a "domestic game" as one might assume is the case in US and UK (Nylander et al., 2018).

\section{SUMMARY AND SOME IDEAS FOR FUTURE RESEARCH}

In this chapter, we have introduced three formative dimensions that we argue play a significant role in constructing "the rules of the game" in contemporary 
academia as well as for adult educational research, more specifically: (i) indexation, (ii) publications and (iii) citations. Bibliometric methods have been hijacked by politicians and policy makers in order to assess the quality of research. However, in this chapter we propose that we as researchers, instead of only critiquing such measurements, should use bibliometrics ourselves in order to create knowledge on our own "localized" publication and citation practices. By doing so, we believe it is possible to give a synthetic and panoramic overview of what kind of research that is being published and cited by colleagues and to foster reflexivity on the fundamental questions posed in any given scientific field (Bourdieu \& Wacquant, 2004). To make the rules of current publication game more transparent could hopefully lead to a well-grounded discussion on what kind of evaluation systems are being implemented across different countries, as well as discussions on how our publication and citation practices could become more balanced in terms of who is publishing, who and what is cited, and what should be deemed to be "quality work" in our own specific research fields.

Another important aspect of the shaping of a research field is the gatekeeping function of journal editors and reviewers (cf. Pontille \& Torny, 2015; Hirschauer, 2015; Lamont \& Huutoniemi, 2011). The peer-review processes and journal publications can represent an important space of possibility for contemporary scholars as well as exercise substantial scholarly constraint. As journals are governed by editorial decisions it is obviously part of the job description of editors and peerreviewers to act as intermediary gatekeepers, controlling the discursive influx to the particular scholarly field (Lewin, 1947a, 1947b). To provide the full story of scholarly recognition, it would be interesting to extend the analysis to include research in other publication formats than journal articles (books, handbooks, educational policy, etc.) as well as to assess, more closely, the gatekeeping work that goes on in the blind peer-view processes. Another aspect of dynamic of scholarly publication and recognition that has not yet been explored extensively is the temporal aspect of the relative impact that individual scholars and research traditions exercised on the field over time. One final bibliometric idea that could be worth pursuing is, therefore, to arrange the bibliographic data in time-series and to take into consideration the emergence and perseverance of the dominating research traditions in a longer time horizon.

\section{NOTES}

1 In the quest to map out the relations between scholars, bibliometrics contains alternatives to the methods used in this paper, see for instance the analysis of "co-citation networks" provided by Persson and colleagues (Person, 1994; Åström et al., 2009).

2 Please note that the editorial work and the country of the publisher does not necessary match. This is partly due to the big publishing houses being located to a specific country for non-academic reasons such as taxation, accounting etc. For instance, this help to explain the rather elevated position of the Netherlands which host a series of international publishers that has editorial teams active elsewhere. 


\section{THE USE OF BIBLIOMETRICS IN ADULT EDUCATION RESEARCH}

3 Self-citations were excluded from the sample as was other document types than articles or reviews (that often do not include reference lists in Scopus). For more on the method used see e.g. Nylander et al. (2018) and Fejes and Nylander (2019).

\section{REFERENCES}

Archambault, E., Campbell, D., Gingras, Y., \& Lariviere, V. (2009). Comparing bibliometric studies obtained from Web of science and Scopus. ArXiv eprint (arxiv:0903.5254).

Åström, F., Åström, F. (Ed.), Danell, R. (Ed.), Larsen, B., \& Schneider, J. W. (2009, June). Celebrating scholarly communication studies: A festschrift for Olle Persson (Vol. 05-S). International Society for Scientometrics and Informetrics.

Bastian, M., Heymann, S., \& Jacomy, M. (2009). Gephi: An open source software for exploring and manipulating networks. International AAAI Conference on Weblogs and Social Media.

Bonitz, M., Bruckner, E., \& Scharnhorst, A. (1997). Characteristics and impact of the Matthew effect for countries. Scientrometrics, 40(3), 407-422.

Bourdieu, P., \& Wacquant, L. (2004). An invitation to reflexive sociology. Cambridge: Polity Press.

Brandom, R. (2008). Untimely review of Hegel's phenomenology of spirit. Topoi, 27, 161-164.

Brown, A. J. (2014). Being REFable: Strategies and tactics in meeting the challenges of the research quality assessment process. In B. Cunningham (Ed.), Professional life in modern UK HE (pp. 14-25). London: IoE Press.

De Solla Price, D. J. (1965). Networks of scientific papers. Science, 149, 510-515.

Desrosières, A. (2008). Pour une sociologie historique de la quantification. L'argument statistique I. Paris: Mines ParisTech.

Fejes, A., \& Nylander, E. (2014). The Anglophone International(e): A bibliometric analysis of three adult education journals, 2005-2012. Adult Education Quarterly, 64(3), 222-239.

Fejes A., \& Nylander, E. (2015). How pluralistic is the research field on adult education? Dominating bibliometrical trends, 2005-2012. European Journal for Research on the Education and Learning of Adults, 6(2), 103-123.

Fejes, A., \& Nylander, E. (2018). Adult education research: Publication strategies and collegial recognition. In M. Milana, S. Webb, J. Holford, R. Waller, \& P. Jarvis (Eds.), Palgrave international handbook of adult and lifelong education and learning (pp. 761-777). London: Palgrave Macmillan.

Fejes, A., \& Nylander, E. (Eds.). (2019). Mapping out the research field of adult education and learning. Dordrecht: Springer.

Gingras, Y. (2014). Criteria for evaluating indicators. In B. Cronin \& C. R. Sugimoto (Eds.), Beyond bibliometrics (pp. 109-125). Cambridge, MA: MIT Press.

Gingras, Y. (2016). Bibliometrics and research evaluation. Cambridge, MA: MIT Press.

Heilbron, J., \& Gingras, Y. (2018). The globalization of European research in the social sciences and humanities (1980-2014): A bibliometric study. In J. Heilbron, G. Sorá, \& T. Boncourt (Eds.), The social and human sciences in global power relations. Socio-historical studies of the social and human sciences (pp. 29-58). Cham: Palgrave Macmillan.

Hirschauer, S. (2015). How editors decide. Oral communication in journal peer review. Human Studies, $38(1), 37-55$.

Hoskin, K. (1996). The 'awful idea of accountability': Inscribing people into the measurement of objects. In R. Munro \& J. Mouritsen (Eds.), Accountability: Power, ethos and the technologies of managing. London: International Thomson Business Press.

Jacomy, M., Venturini, T., Heymann, S., \& Bastian, M. (2014). ForceAtlas2, a continuous graph layout algorithm for handy network visualization designed for the Gephi software. PLOS ONE 9(6), e98679.

Karpik, L. (2011). What is the price of a scientific paper? In J. Beckert \& P. Aspers (Eds.), The worth of goods: Valuation and pricing in the economy (pp. 63-85). New York, NY: Oxford University Press.

Lamont, M., \& Huutoniemi, K. (2011). Comparing customary rules of fairness: Evaluative practices in various types of peer review panels. In C. Camic, N. Gross, \& M. Lamont (Eds.), Social knowledge in the making (pp. 209-232). Chicago, IL: University of Chicago Press.

Larsson, S. (2009). An emerging economy of publications and citations. Nordisk Pedagogik, 29, 34-52. 


\section{E. NYLANDER ET AL.}

Larsson, S., Fejes, A., Österlund, L., \& Nylander, E. (2019). Invisible colleges in research on adult learning: A bibliometric study on international scholarly recognition. In A. Fejes \& E. Nylander (Eds.), Mapping out the research field of adult education and learning. Dordrecht: Springer.

Lewin, K. (1947a). Frontiers in group dynamics: Concept, method and reality in social science; social equilibria and social change. Human Relations, 1(1), 5-40.

Lewin, K. (1947b). Frontiers in group dynamics II. Channels of group life; social planning and action research. Human Relations, 1(2), 143-153.

Martin, B. R. (2011). The research excellence framework and the 'impact agenda': Are we creating a Frankenstein monster? Research Evaluation, 20(3), 247-254.

Merton, R. K. (1973). The sociology of science: Theoretical and empirical investigations (Norman W. Storer, Ed.). Chicago, IL: The University of Chicago Press.

Ministry of Education. (2007). Resurser för kvalitet. Stockholm: Ministry of Education.

Nylander, E., Österlund, L., \& Fejes, A. (2018). Exploring the adult learning research field by analysing who cites whom. Vocations and Learning, 11(1), 113-131.

Persson, O. (1994). The intellectual base and research fronts of "jasis" 1986-1990. Journal of the American Society for information Science, 45(1), 31-38.

Pontille, D., \& Torny, D. (2015). From manuscript evaluation to article valuation: The changing technologies of journal peer review'. Human Studies, 38(1), 57-79. 